\title{
THE PURIFICATION AND PROPERTIES OF STREPTOLYSIN S
}

\author{
By Bernhard Cinader,* Ph.D., and LOUIS PILlemer, Ph.D.
}

(From the Institute of Pathology, Western Reserve University, Cleveland)

(Received for publication, May 25, 1950)

Marmorek (1) in 1895 first noted the ability of some streptococci to lyse red blood corpuscles, and about 40 years later Todd (2) showed that two distinct substances produced by these organisms could cause hemolysis; one called streptolysin $O$ because it could be reversibly oxidized; the other streptolysin $\mathrm{S}$ because it could be obtained by shaking the organisms with serum.

While considerable advances were made in the purification of streptolysin $O$ $(3 a, b, 4)$, great difficulties were encountered in the purification of streptolysin $\mathrm{S}$. The available streptolysin S $(3 c)$ was always associated with high concentrations of serum proteins, and the hemolysin was therefore precipitated with serum proteins. This difficulty was removed when Okamoto (5) found that addition of yeast nucleic acid to the medium caused a 1000 to 5000 -fold increase of streptolysin in culture filtrates. Ito (6), who surveyed the properties of the lysin prepared under these conditions, showed that it was apparently identical with the streptolysin S described by Todd. Okamoto et al. (5) prepared purified lysin of considerable potency; however, their data are insufficient to gauge the degree of purification and the yields achieved. Bernheimer and Rodbart (7) demonstrated that sodium nucleate digested by ribonuclease was more effective than the native nucleate employed by Okamoto (5) and that, in the presence of this factor, maltose promoted the production of streptolysin $\mathrm{S}$. The addition of these two factors to the synthetic medium previously described by Bernheimer, Gillman, Hottle, and Pappenheimer (8) resulted in the production of highly potent filtrates of streptolysin $\mathrm{S}$.

It seemed of interest to attempt isolation of streptolysin $\mathrm{S}$ from these filtrates to determine the nature and role of the lysin. Furthermore, since most studies on the kinetic properties of lysins have been carried out with crude filtrates it seemed important to conduct such experiments with highly purified hemolysin. Substrate studies were also undertaken in an attempt to gain further information about the surface of the red cell.

The variable phase method employing methanol under controlled conditions of $\mathrm{pH}$, ionic strength, temperature, etc., was employed in fractionation studies. This method makes use of the general principles developed by Cohn (9) and his coworkers for the fractionation of plasma proteins with ethanol-water

\footnotetext{
* Present address: Lister Institute of Preventive Medicine, London.
} 
mixtures. Some theoretical and practical aspects of the method as applied to bacterial antigens are discussed elsewhere (10).

\section{EXPERIMENTAL}

Parent filtrates of streptolysin S were prepared by the methods of Bernheimer et al. $(7,8)$ employing Streptococcus pyogenes, strain C203S. Casein ${ }^{1}$ hydrolyzed with hydrochloric acid instead of casein hydrolyzed with sulfuric acid was employed as the source of nitrogen. The quantity of potassium chloride in the medium was reduced to compensate for the chloride introduced with the casein. Growth was maintained for 14 hours at $37^{\circ}$ and the organisms were then centrifuged at $2^{\circ}$. The supernatant obtained in this manner was employed in fractionation.

Nitrogen was determined in duplicate by the micro-Kjeldahl method of Pregl.

Iodine numbers were determined by the method of Hanus (11).

Ionic strength was determined by calculation after the addition of all reagents to the system. The ionic content of precipitates was neglected and the designated ionic strength is that of added ions. When hydrochloric acid was added to sodium acetate, the ionic strength was taken to be due to the acetate only, if the acetate was in excess; and with an excess of hydrochloric acid it was considered to be due entirely to the hydrochloric acid. For the first step, the ionic strengths were calculated on the assumption that the ionic strength of the starting material was 0.13 .

The $\mathrm{pH}$ was measured with the glass electrode (Cambridge research model) before the addition of alcohol.

Analytic electrophoresis was carried out with microcells $(2 \mathrm{ml}$.) in a Tiselius apparatus employing the optical system of Longsworth. The same apparatus was used for preparative electrophoresis, except that a cylindrical lens was employed to permit continuous visual observation. Cells of a capacity of $11 \mathrm{ml}$. were employed. Phosphate buffer ionic strength of 0.2 was employed throughout.

Fractionation Melhods.-Aliquots of the culture filtrate were cooled to $1^{\circ}$ and acetic acid chilled to $1^{\circ}$ was added to obtain the desired $\mathrm{pH}$ values. The liquid was then transferred to a bath at $-25^{\circ}$ and calculated amounts of alcohol cooled to $-25^{\circ}$ and measured at that temperature were added slowly with constant stirring, the mixture being continuously maintained near its freezing point. The percentage of methanol is stated as the concentration of alcohol in the final volume. The mixtures were then kept at $-5^{\circ}$ for at least 12 hours, and finally centrifuged at $-5^{\circ}$.

After the optimum point of precipitation had been found, the optimum conditions for extraction were investigated. Phosphate saline (pH 6.9) was used for the extraction of the precipitates in the exploration of solubility behavior. A layer of the solvent was run carefully over the precipitate and the whole preparation was kept at $-5^{\circ}$. After about 30 minutes the supercooled liquid could be made to "snap freeze." The precipitate was mixed with the ice crystals and the mixture allowed to thaw at $1^{\circ}$, and to stand at that temperature overnight for extraction to occur.

The clarified extracted material was immediately divided into aliquots, stored at $-35^{\circ}$, and appropriate quantities were thawed as required. Further precipitations were carried out with solutions considerably more dilute than those which had been stored.

Assay of Hemolytic Activity.-One hemolytic unit $(1 \mathrm{H} . \mathrm{U}$.$) is defined as that amount of$ hemolysin which will lyse half the erythrocytes contained in $2 \mathrm{ml}$. of a 0.5 per cent suspension of rabbit blood corpuscles in phosphate saline $(\mathrm{M} / 12.9 \mathrm{NaCl}$ and $\mathrm{M} / 15$ mono- and disodium phosphate) of $\mathrm{pH} 6.85 \pm 0.05$ at $37 \pm 0.5^{\circ}$ within 30 minutes. Blood collected in citrate was

${ }^{1}$ Bacto-casamino acids (Difco). 
obtained from the marginal vein of the rabbit's ear; five rabbits were used and bled successively on different days. The red cells were washed three times with the phosphate buffer, and finally suspended in the buffer solution to give a 1 per cent suspension. Three ml. of the red cell suspension and appropriate volumes of buffer were incubated at $37^{\circ}$ for 5 minutes, the hemolysin was then added, and the tubes mixed by inversion, care being taken to loosen the rubber stoppers to release trapped fluid. The final volume in each case was $6 \mathrm{ml}$. At the end of 30 minutes at $37^{\circ}$, the tubes were centrifuged for 4 to 5 minutes at $2^{\circ}$, at 2,000 to 2,500 R.P.M. The supernatant was decanted into Klett tubes and the hemoglobin determined in the Klett colorimeter.

The blank was prepared by mixing $3 \mathrm{ml}$. of suspension with $3 \mathrm{ml}$. phosphate saline. The supernatant was used to adjust the null point of the colorimeter. A 50 per cent standard was prepared by mixing $1.5 \mathrm{ml}$. of cell suspension with $4.5 \mathrm{ml}$. of buffer, lysing completely with saponin, and centrifuging clear. The 50 per cent standard was read simultaneously with each test to compensate for a possible drift in the instrument.

Since the hemolysin $S$ is unstable at the high dilutions used, fresh dilutions were made.up 5 minutes before each test.

The fragility of erythrocytes from different rabbits was found to vary considerably, and this could not be avoided by using the same animal throughout, because repeated bleeding also leads to changes in the fragility of the cells. Furthermore, the fragility of the cells was found to vary during the 8 to 10 hour period in which they were used. Fragility appears to decrease at first and then to increase steadily. Errors due to variations in the blood cell suspensions could be eliminated by testing a standard simultaneously with the unknown material, and expressing the potency in terms of this standard material. Therefore, the preceding fraction from which the preparation was obtained was tested at the same time as the material of unknown potency. The percentage yield is thus independent of cell variations.

The changes which occurred in the cells during the test period were compensated for by redetermining the standard at 90 minute intervals, and the percentage yield was then determined for each set of results and, finally, the average of the values was taken. Every new preparation was tested at least in duplicate, but usually in triplicate. Consecutive tests were made at decreasing increments of lysin concentration, the final tests at increments of 2 to 4 per cent.

Under the conditions of this test, absolute methanol appears to contain about $3 \mathrm{H} . \mathrm{U} . / \mathrm{ml}$. In view of the small amounts of methanol in redissolved precipitates and high dilution of extracts employed for testing, no special corrections are required for methanol. Throughout this paper results are given as hemolytic units per milligram of nitrogen (H.U./mg. N).

\section{The Fractionation of Streplolysin $S$}

Preparation of Precipitate $I(P I)$.-The hemolysin could be precipitated with 40 per cent methanol in quantitative yield between $\mathrm{pH} 4.9$ and 4.35 at an ionic strength of 0.07 to 0.075 (Table $\mathrm{I} a$ ). A decrease of alcohol in this $\mathrm{pH}$ range or a decrease in ionic strength led to a decrease in yield. It was noted that the degree of purification in the fractionation of streptolysin S was dependent on the potency of the starting material (Table I c c).

$P$ I was extracted with various diluents in volumes of two-fifths of the original volume of crude filtrate (Table I $b$ ). Sodium acetate adjusted with hydrochloric acid or sodium hydroxide to $\mathrm{pH} 4.75-7.9$ within a range of ionic strength 0.05 to 0.3 was found to extract not more than 43 per cent of the material precipitated. The ionic strength effect was not very marked in acetate between 0.1 to 0.25 , but below and above these limits the yield decreased markedly. Increasing the $\mathrm{pH}$ of extraction to 7.9 seemed to increase the yield slightly. Ninety-six per cent of the activity could be extracted either with 0.05 M sodium bicarbonate or $0.15 \mathrm{M}$ trisodium citrate. 


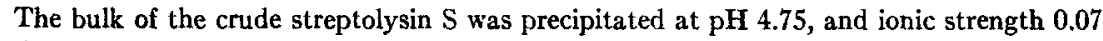
in the presence of 40 per cent methanol at $-5^{\circ}$. The material was then extracted with onethirtieth of its original volume of $0.15 \mathrm{M}$ sodium citrate in order to reduce the volume at this step (P I).

Preparation of Precipitate II (P II).-The P I used in the further purification of the streptolysin S contained $0.226 \mathrm{mg}$. N/ml. and $20,000 \mathrm{H} . \mathrm{U} . / \mathrm{ml}$. This material was diluted for further fractionation to 5 or 10 times its original volume with distilled water and the $\mathrm{pH}$ adjusted with $1 \mathrm{M}$ citric acid. When the ionic strength desired was higher than could be obtained in this manner a suitable acetate buffer was employed as the diluent.

TABLE I $a$

The Precipitation of Streptolysin S from Parent Filtrates under Varying Conditions of $p H$, Ionic Strength, and Methanol Concentration at $-5^{\circ} \mathrm{C}$.

\begin{tabular}{|c|c|c|c|c|c|}
\hline Starting material & pH & Ionic strength & Methanol & $\underset{N^{*} \times 10^{3}}{\text { H.U./mg. }}$ & Yield \\
\hline & & & per cent & & per cent \\
\hline$a$ & 6.9 & 0.039 & 40 & 21.6 & 19 \\
\hline$a$ & 6.2 & 0.039 & 40 & 26.5 & 19 \\
\hline$a$ & 5.4 & 0.038 & 40 & 54.5 & 43 \\
\hline$a$ & 4.25 & 0.037 & 40 & 36.4 & 39 \\
\hline$a$ & 3.50 & 0.026 & 40 & 32.1 & 40 \\
\hline$b$ & 7.15 & 0.078 & 40 & 13.6 & 39 \\
\hline$b$ & 8.25 & 0.077 & 40 & 13.5 & 29 \\
\hline$c$ & 5.48 & 0.079 & 40 & 30.3 & 56 \\
\hline$b$ & 5.35 & 0.072 & 40 & 32.9 & 76 \\
\hline$c$ & 4.88 & 0.074 & 40 & 53.3 & 100 \\
\hline$b$ & 4.35 & 0.060 & 40 & 36.7 & 100 \\
\hline$c$ & 4.34 & 0.069 & 40 & 55.3 & 104 \\
\hline$c$ & 4.16 & 0.065 & 40 & 42.2 & 87 \\
\hline$c$ & 3.97 & 0.059 & 40 & 43.2 & 87 \\
\hline$b$ & 3.65 & 0.033 & 50 & 30.0 & 92 \\
\hline$a$ & 4.78 & 0.090 & 25 & 12.9 & 48 \\
\hline
\end{tabular}

Parent $a$ H.U./mg. N $0.985 \times 10^{3}$.

"b " " " $0.466 \times 10^{3}$.

"c " " " $0.545 \times 10^{3}$.

* Hemolytic units per milligram of nitrogen.

It will be seen (Table II $a$ ) that conditions which precipitated the hemolysin quantitatively from the starting material brought about much less complete precipitation when applied to $\mathrm{P}$ I. The methanol required for complete precipitation under these conditions was 25 per cent.

It was also noted that P I could be precipitated in the absence of alcohol, but precipitation of the active principle was far from complete within the range investigated (Fig. 1). The yield increased on lowering the $\mathrm{pH}$. Material precipitated at $\mathrm{pH} 3.8$, ionic strength 0.135 with 25 per cent alcohol was extracted with various solvents (Table II $b$ ). The influence of certain metal salts on the solubility of streptolysin $S$ was explored at this step. These salts offered no advantage under present conditions. Sodium acetate $0.15 \mathrm{M}$ proved suitable for redissolving this precipitate, although it had extracted only about 40 per cent of the activity from $P$ I. 
TABLE I $b$

The Extraction of Precipitate I

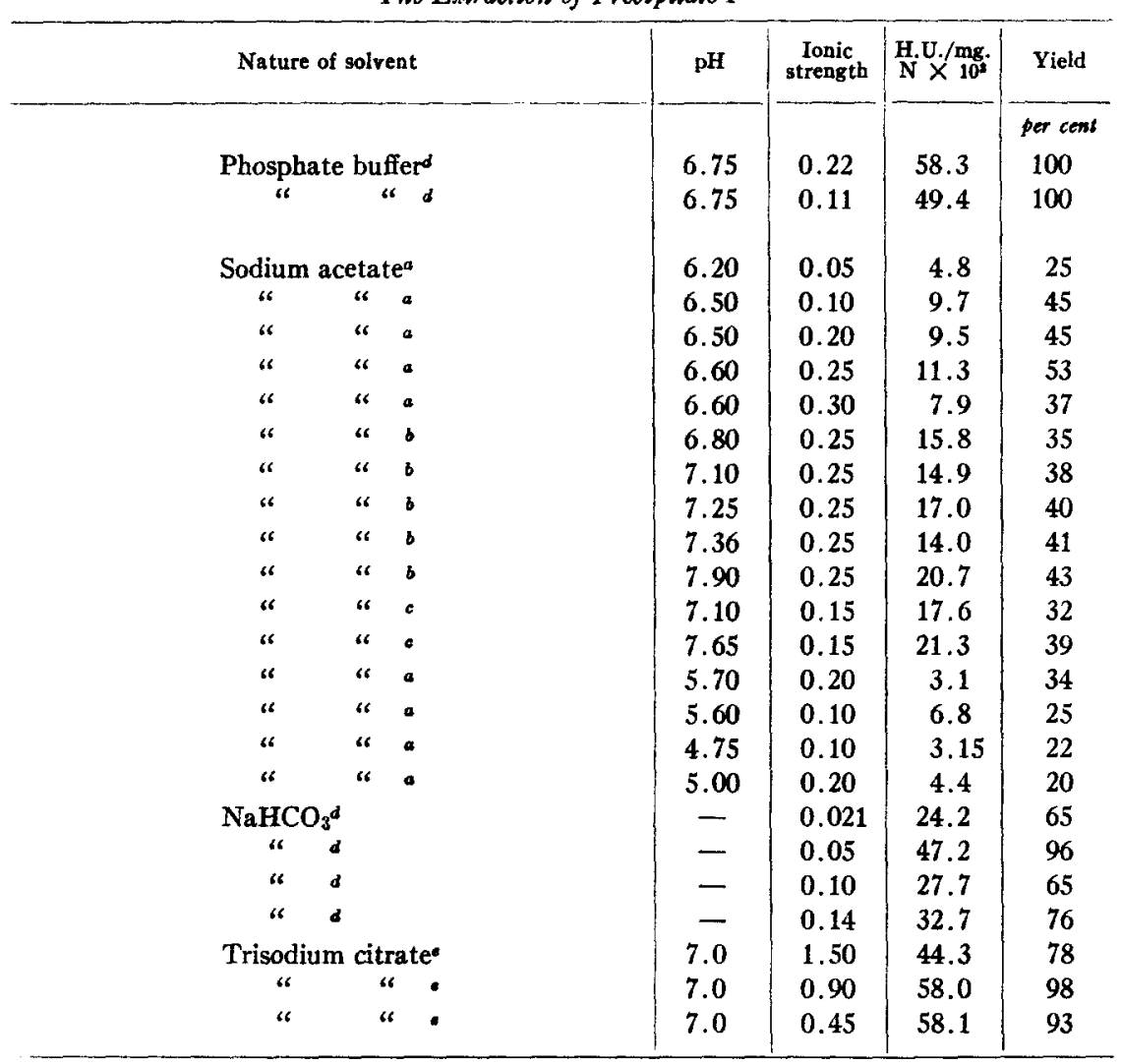

"Parent H.U./mg. N $0.269 \times 10^{3}$.

" " " " " $0.488 \times 10^{3}$.

c " " " " $0.494 \times 10^{3}$.

d " " " " " $0.545 \times 10^{8}$.

- " " " $60.783 \times 10^{8}$.

TABLE I $c$

The Dependence of the Purification Factor on the Potency of the Starting Material

\begin{tabular}{c|c|c|c}
\hline \multicolumn{2}{c|}{ Starting material } & P I & Purification factor* \\
\hline H.U./ml. & H.U./mg. N & H.U./mg. N $\times 10^{3}$ & \\
\hline 600 & 270 & 23.1 & 86 \\
1570 & 545 & 53.3 & 98 \\
\hline
\end{tabular}

* (H.U./mg. N) purified fraction

(H.U./mg. N) starting material 
TABLE II $a$

The Fractionation of $P I$ at $-5^{\circ}$ under Controlled Conditions of $p H$ and Ionic Strength in the Presence of 25 to 40 Per Cent Methanol

\begin{tabular}{|c|c|c|c|c|}
\hline $\mathrm{pH}$ & Ionic strength & Methanol & H.U. $/ \mathrm{mg} . \mathrm{N} \times 10^{3}$ & Yield \\
\hline & & per cent & & per cent \\
\hline 4.35 & 0.103 & $40^{*}$ & 117.1 & 67 \\
\hline 4.53 & 0.113 & $40^{*}$ & 100.1 & 73 \\
\hline 4.55 & 0.121 & $40^{*}$ & 82.0 & 48 \\
\hline 4.75 & 0.126 & $40^{*}$ & 120.7 & 74 \\
\hline 4.77 & 0.185 & $40^{*}$ & 87.3 & 22 \\
\hline 4.62 & 0.184 & $40^{*}$ & 88.1 & 27 \\
\hline 4.81 & 0.186 & $40^{*}$ & 100.3 & 18 \\
\hline 4.84 & 0.184 & $40^{*}$ & 96.7 & 22 \\
\hline 4.52 & 0.181 & 40 & 88.1 & 56 \\
\hline 4.62 & 0.182 & 40 & 73.5 & 46 \\
\hline 3.76 & 0.108 & 40 & 137.9 & 95 \\
\hline 3.96 & 0.108 & 40 & 146.3 & 88 \\
\hline 4.05 & 0.108 & 40 & 118.4 & 92 \\
\hline 4.45 & 0.108 & 40 & 99.6 & 69 \\
\hline 4.50 & 0.108 & 40 & 115.0 & 73 \\
\hline 4.85 & 0.108 & 40 & 93.5 & 60 \\
\hline 4.39 & 0.134 & 25 & 87.2 & 72 \\
\hline 4.60 & 0.134 & 25 & 86.8 & 63 \\
\hline 4.82 & 0.135 & 25 & 67.4 & 49 \\
\hline 3.37 & 0.135 & 25 & 111.8 & 78 \\
\hline 3.55 & 0.135 & 25 & 140.8 & 85 \\
\hline 3.60 & 0.126 & 25 & 144.7 & 91 \\
\hline 3.62 & 0.135 & 25 & 132.5 & 85 \\
\hline 3.65 & 0.135 & 30 & 113.4 & 85 \\
\hline 3.66 & 0.135 & 25 & 154.0 & 92 \\
\hline 3.68 & 0.135 & 25 & 108.3 & 84 \\
\hline 3.80 & 0.135 & 25 & 170.5 & 103 \\
\hline 3.82 & 0.135 & 25 & 147.3 & 110 \\
\hline 3.87 & 0.135 & 25 & 129.1 & 98 \\
\hline 3.93 & 0.135 & 25 & 132.1 & 95 \\
\hline
\end{tabular}

* The starting material was diluted to a concentration of $0.0228 \mathrm{mg} . \mathrm{N} / \mathrm{ml}$.; in all other preparations it was $0.0455 \mathrm{mg}$. N/ml. before addition of alcohol.

TABLE II $b$

The Extraction of Precipitate II

\begin{tabular}{|c|c|c|c|}
\hline Nature of solvent & $\mathrm{pH}$ & 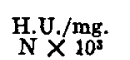 & Yield \\
\hline & & & per cent \\
\hline $\mathrm{CaCl}_{2} 0.01 \mathrm{M}$ & 4.25 & 51.9 & 15 \\
\hline " $0.1 \mathrm{M}$ & 3.71 & 130.15 & 61 \\
\hline “ $\quad 0.3 \mathrm{M}$ & 3.92 & 111.1 & 63 \\
\hline $\mathrm{SrCl}_{2} 0.2 \mathrm{M}$ & 3.63 & 108.3 & 76 \\
\hline Phosphate buffer $0.15 \mathrm{M}$ & 6.80 & 135.7 & 91 \\
\hline Sodium acetate $0.15 \mathrm{M}$ & 6.42 & 148.6 & 105 \\
\hline " citrate $0.10 \mathrm{M}$ & 6.9 & 159.85 & 107 \\
\hline " $\quad 0.15 \mathrm{M}$ & 6.9 & 130.1 & 86 \\
\hline " $0.5 \mathrm{M}$ & 6.9 & 159.4 & 105 \\
\hline
\end{tabular}


On the basis of the foregoing experiments, fraction $\mathrm{P} I$ was diluted with 4 volumes of distilled water, and the $\mathrm{pH}$ was adjusted to 3.8 with $1 \mathrm{M}$ citric acid. The solution was kept at $0^{\circ}$ and all reagents were chilled to $1^{\circ}$ and then added. Methanol was then added slowly to a final concentration of 25 per cent, and the mixture was then maintained at $-5^{\circ}$. The centrifuged precipitate was taken up to one-third of the original volume of $\mathrm{PI}$ in $0.15 \mathrm{M}$ sodium acetate (P II). Fraction P II contained $0.35 \mathrm{mg}$. N/ml. and 61,800 H.U./ml.

Preparation of Precipitate $I I I$ ( $P I I I)$.- - For the next step, P II was generally diluted 5 times (Table III). In the following experiments, attempts were made to precipitate streptoly$\sin \mathrm{S}$ at $\mathrm{pH}$ values more alkaline than those used in the previous steps. However, either the purification or the yield was unsatisfactory under these conditions. It was soon noticed that

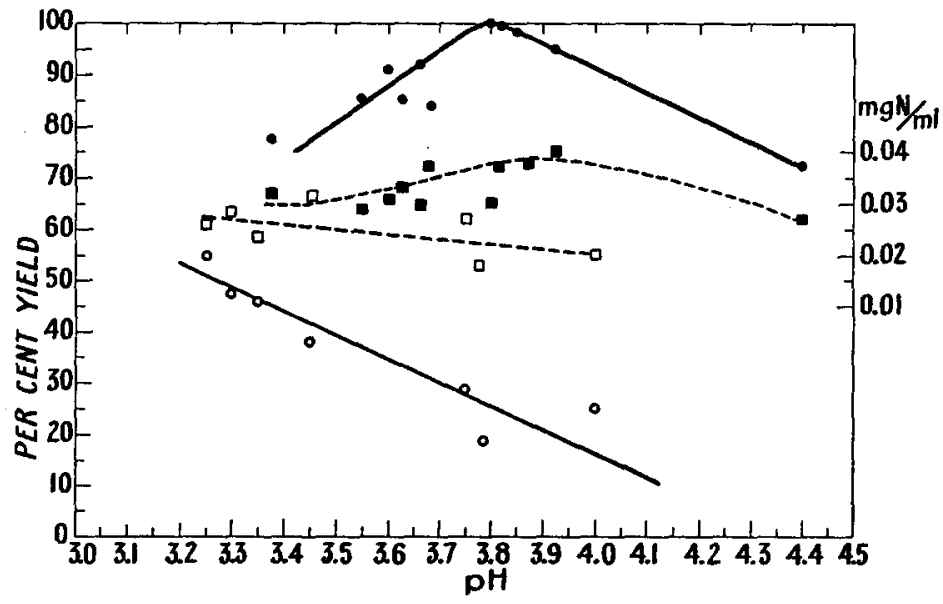

FIG. 1. The precipitation of streptolysin $S$ from fraction $P$ I.

$\bullet$, yield in H.U. per cent

, mg. $\mathrm{N} / \mathrm{ml}$. of redissolved precipitate

$O$, yield in H.U. per cent

$\square, \mathrm{mg} . \mathrm{N} / \mathrm{ml}$. of redissolved precipitate

lobtained by precipitation in the presence of 25 per cent alcohol. obtained by precipitation in the absence of alcohol.

complete precipitation of streptolysin could be obtained at this stage under appropriate hydrogen ion concentrations in the absence of alcohol. This was explored as a function of ionic strength, employing sodium acetate, acetic acid, and hydrochloric acid. Systematic studies were carried out at ionic strengths of 0.03 and 0.15 as a function of $\mathrm{pH}$ (Fig. 2). The difference in the solubility of streptolysin $S$ at these two levels of ionic strength proved to be very remarkable. Maximum precipitation occurred between $\mathrm{pH} 3.1$ to 3.23 at ionic strength 0.03 . At ionic strength 0.14 , complete precipitation of active material occurred over a much wider range and at a more acid condition ( $\mathrm{pH} 1.8-2.4)$. The decrease in precipitated nitrogen on the acid side of this range allowed considerable purification.

On the basis of the preceding observations, 4 volumes of $0.15 \mathrm{M}$ sodium acetate were added to $\mathrm{P} \mathrm{II}$, and the solution was adjusted to $\mathrm{pH} 1.46$ with $1 \mathrm{M}$ hydrochloric acid. The mixtures were maintained at $1^{\circ}$ for 2 hours. The centrifuged precipitates were dissolved to one-ninth the original volume of $\mathrm{P}$ II in $0.15 \mathrm{~m}$ sodium acetate. The $\mathrm{pH}$ of the solution was then adjusted to 7.2 with $1 \mathrm{~N} \mathrm{NaOH}$ (P III). The limited quantity of material available prevented further purification by fractional precipitation. It was considered that P III was sufficiently pure for studies of some of the properties of streptolysin S. 


\section{The Properties of Streptolysin $S$}

The P III contained $1.28 \mathrm{mg}$. N/ml. and $500,000 \mathrm{H} . \mathrm{U} . / \mathrm{ml}$. P III could be resolved into two electrophoretic components. One comprised 60 per cent of the total with a mobility of $15.8 \times 10^{-5} \mathrm{~cm} .{ }^{2} / \mathrm{sec}$. $/$ volt; the other had a mobility of $7.4 \times 10^{-5} \mathrm{~cm} .{ }^{2} / \mathrm{sec}$. $/$ volt in phosphate buffer of $\mathrm{pH} 7.8$ and ionic strength 0.2 (Fig. 3). The material was analyzed at refractive increment 0.0006 . P III

TABLE III

The Fractionation of $P I I$

\begin{tabular}{|c|c|c|c|c|c|}
\hline Ionic strength & $\mathrm{pH}$ & Methanol & Temperature & $\underset{\mathbf{N} \times{ }^{\mathbf{H}} \mathbf{U}}{\mathbf{U}} \cdot \mathbf{m g}$. & Yield \\
\hline & & per cent & ${ }^{\circ} \mathrm{C}$ & & per cent \\
\hline 0.623 & 7.25 & 25 & -5 & 78.8 & 75 \\
\hline 1.938 & 7.14 & 40 & -5 & 92.9 & 8 \\
\hline 0.173 & 6.55 & 25 & -5 & 81.0 & 19 \\
\hline 0.088 & 6.52 & 25 & -5 & 209.2 & 59 \\
\hline 0.018 & 6.02 & 40 & -5 & 158.4 & 38 \\
\hline 0.090 & 5.85 & 25 & -5 & 190.6 & 74 \\
\hline 1.804 & 5.46 & 25 & -5 & 341.5 & 55 \\
\hline 0.030 & 3.70 & - & +1 & 208.8 & 93 \\
\hline 0.030 & 4.00 & - & +1 & 170.2 & 60 \\
\hline 0.030 & 3.78 & - & +1 & 208.5 & 85 \\
\hline 0.030 & 3.56 & - & +1 & 210.8 & 87 \\
\hline 0.030 & 3.20 & - & +1 & 256.0 & 100 \\
\hline 0.030 & 3.03 & - & +1 & 263.8 & 88 \\
\hline 0.030 & 2.75 & - & +1 & 123.5 & 47 \\
\hline 0.030 & 2.45 & - & +1 & 167.3 & 46 \\
\hline 0.090 & 1.31 & - & +1 & 344.3 & 81 \\
\hline 0.131 & 3.00 & - & +1 & 266.4 & 91 \\
\hline 0.129 & 2.46 & - & +1 & 266.4 & 100 \\
\hline 0.167 & 1.85 & - & +1 & 258.3 & 100 \\
\hline 0.162 & 1.43 & - & +1 & 333.8 & 92 \\
\hline 0.164 & 1.41 & - & +1 & 354.6 & 100 \\
\hline 0.135 & 1.08 & - & +1 & 241.2 & 51 \\
\hline 0.228 & 3.00 & - & +1 & 176.2 & 65 \\
\hline 0.234 & 1.82 & - & +1 & 208.5 & 86 \\
\hline
\end{tabular}

was dark brown and had to be diluted to allow the passage of light. All the pigment migrated with the slower of these two components. Electrophoretic separation was employed to determine which of these two components was responsible for hemolysis. It was easy to isolate the fast component, but the slow component which carried the pigment is rather polydisperse, and its peak flattens out in the time required for the experiment. In order to separate the slow component, use was made of the observation that the absorption ran parallel with the peak of the Gaussian curve representing it over the whole 
period in which the curve was not too diffuse for observation. These fractions were examined for hemolytic activity. The "colorless" fast component contained $700 \mathrm{H.U} . / \mathrm{ml}$. while no activity was found in the slow fraction. Electrophoretically isolated material was used in some of the kinetic experiments described in the following section.

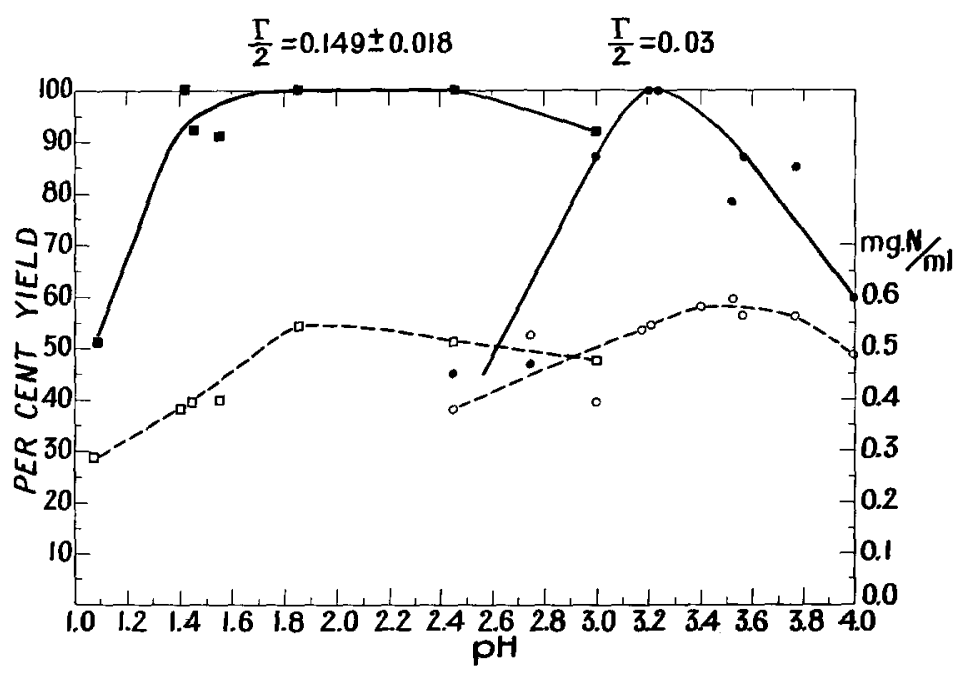

FIG. 2. The fractionation of $P$ II.

口, •, yield H.U per cent.

$\square, 0, \mathrm{mg} . \mathrm{N} / \mathrm{ml}$. in the redissolved precipitate.

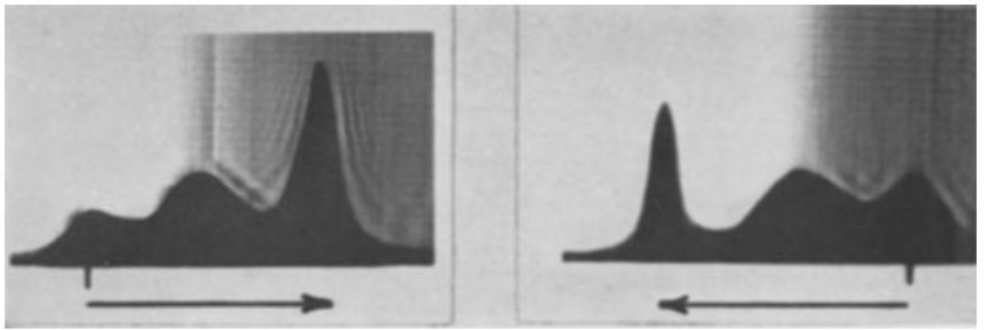

Fig. 3. Electrophoresis of streptolysin S (P III). $\Delta n=0.00057, t=3600$ sec., 0.007 apm., phosphate buffer $\mathrm{pH} 7.85$, ionic strength 0.2 .

Fraction P III was stable in the frozen state, and showed no decrease in activity when stored at $1^{\circ}$ for 4 weeks. P III diluted 1:11 lost approximately 40 per cent of its original activity in the same period of time. The material could be dialyzed against daily changes of either phosphate buffer or water for 4 days at $1^{\circ}$ without loss of activity. However, the material which had been dialyzed against distilled water became partially insoluble after standing 
at $1^{\circ}$ for 10 days. The portion insoluble in distilled water redissolved in $0.15 \mathrm{M}$ citrate or in phosphate buffer contained only 2 per cent of the original activity and the material that had remained in solution 28 per cent. Electrophoretic examination showed that these fractions contained both components in approximately the same proportions.

In view of the potentiating action of magnesium and calcium ions on the

TABLE IV

The Inhibition Phase in the Interaction between Streptolysin $S$ and Erythrocyles

\begin{tabular}{|c|c|c|c|c|c|c|}
\hline \multirow[b]{4}{*}{$30 \mathrm{~min}$. at $37^{\circ} \mathrm{C}$. } & \multicolumn{6}{|c|}{ (a) } \\
\hline & \multirow[t]{2}{*}{ Streptolysin S, ml. } & 0.2 & 0.4 & 0.8 & 1.6 & 3.0 \\
\hline & & \multicolumn{5}{|c|}{ Hemolysis, per cent } \\
\hline & & 3 & 31 & 81 & 86 & 98 \\
\hline & \multicolumn{6}{|c|}{ (b) } \\
\hline & \multirow[t]{2}{*}{ Streptolysin S, $m l$. } & 0.2 & 0.4 & 0.8 & 1.6 & 3.0 \\
\hline & & \multicolumn{5}{|c|}{ Hemolysis, per cent } \\
\hline \multirow[t]{2}{*}{$30 \mathrm{~min}$. at $14^{\circ} \mathrm{C}$. } & A & 0 & 3 & 19 & 28 & 59 \\
\hline & B & & & 72 & 86 & 98 \\
\hline \multirow[t]{2}{*}{60 " “ " " } & $A$ & & & 37 & 59 & 73 \\
\hline & $\mathrm{I}$ & & & 66 & 77 & 89 \\
\hline \multirow[t]{5}{*}{90 “ “ “ } & A & & & 49 & 68 & 75 \\
\hline & $\mathrm{B}$ & & & 57 & 89 & 111 \\
\hline & \multicolumn{6}{|c|}{ (c) } \\
\hline & \multirow[t]{2}{*}{ Streptolysin S, $m !$} & 0.2 & 0.4 & 0.8 & 1.6 & 3.0 \\
\hline & & \multicolumn{5}{|c|}{ Hemoly sis, per cent } \\
\hline $90 \mathrm{~min}$. at $14^{\circ} \mathrm{C}$ & & 0 & 0 & 0 & 0 & 21 \\
\hline
\end{tabular}

action of $\alpha$-lecithinase (12), it was thought worth while to see what effect their presence had on hemolytic action of streptolysin S. P III was dialyzed against distilled water and its activity was then tested in the usual manner, replacing the phosphate saline buffer with physiological saline. The lysin dissolved in $0.15 \mathrm{M}$ saline was adjusted in one case to $0.02 \mathrm{M} \mathrm{MgCl}_{2}$ and in the other to $0.02 \mathrm{M} \mathrm{CaCl}_{2}$. Whereas the dialyzed toxin had $225,000 \mathrm{H} . \mathrm{U} . / \mathrm{ml}$. in the presence of sodium chloride only, and $173,000 \mathrm{H} . \mathrm{U} . / \mathrm{ml}$. in the presence of $\mathrm{MgCl}_{2}$ and $\mathrm{NaCl}$, it had only $62,500 \mathrm{H}$.U. in the presence of calcium. It therefore appears that calcium is an inhibitor under the conditions of the experiment. 


\section{Kinetics of Bemolytic Action}

The Inhibition Period in the Action of Streptolysin S.-When 2 to 3 units of streptolysin $\mathrm{S}$ are mixed with red cells at $14^{\circ}$, hemolysis begins only after $1 \frac{1}{2}$ hours. If the red cells are centrifuged, about 70 per cent of the hemolysin is found in the supernatant, as shown by adding fresh red cells and incubating at $37^{\circ}$ for 30 minutes. Nevertheless, the hemolysin has already acted on or combined with the original red cells, which can be demonstrated by suspending the red cells after careful washing, in fresh phosphate buffer and incubating at $37^{\circ}$ for 30 minutes.

Varying amounts of streptolysin S were incubated with $3 \mathrm{ml}$. portions of red cell suspensions for 30 minutes at $37^{\circ}$ in a total volume of $6 \mathrm{ml}$. (Table IV a). Similar mixtures were kept at $14^{\circ}$ for 30 minutes, 60 minutes, and 90 minutes. The tubes were centrifuged. The cells were suspended in phosphate buffer (A). The supernatants were added to cells from $3 \mathrm{ml}$. of fresh suspension (B). Both sets of tubes were kept at $37^{\circ}$ for 30 minutes. The results are presented in Table IV $b$.

It will be seen that there was a small decrease of hemolysin in the liquid phase and a progressive modification of the blood corpuscles during incubation. The change did not lead directly to hemolysis at the low temperature because at $14^{\circ}$ the greatest degree of lysis shown, after 90 minutes, is 21 per cent (Table IV c).

\section{The Rate of Hemolysis as a Function of Temperature.-}

The Arrhenius equation (13) may be written as follows:-

$$
v=z e^{-\mu / R T}
$$

Where $v$ is the velocity of the reaction, $z$ is a constant, $e$ is the base of the natural logarithms, $T$ is the absolute temperature, $R$ is the gas constant and $\mu$ is the critical thermal increment or energy of activation; i.e., the amount of energy per mole over and above the average energy that molecules must acquire before they can react. ${ }^{2}$ The slopes of the linear part of the sigmoid plots of percentage hemolysis against time were measured for this purpose.

The conditions of the following experiments were analogous to those employed for the hemolytic test ( $\mathrm{pH} 6.85 \pm 0.05$ ). The final volume of the mixture was $100 \mathrm{ml}$. All experiments were carried out in accurately controlled constant temperature baths. Aliquots of the mixture were withdrawn at suitable intervals of time and centrifuged at $1^{\circ}$. The temperature range was taken between $14^{\circ}$ and $40^{\circ}$. The experiments were carried out with P III at two concentrations and with the electrophoretically separated fraction. Percentage hemolysis was plotted against time for each temperature and concentration and the rate of hemolysis was determined from the straight part of the sigmoid curve.

Fig. 4 shows that the plot of $\log _{e}$ (rate of hemolysis) against the reciprocal of the absolute temperature gives a straight line relationship over the temperature range indicated, and that the slopes of the lines are parallel over a

${ }^{2}$ Crozier (14) calls $\mu$ "the temperature characteristic" to indicate that in biological systems it is not necessarily identical with the energy of activation. 
twofold range of concentration; i.e., that $\mu$ is independent of concentration over this range, which is, of course, a condition for the validity of the equation. The electrophoretically isolated fraction gives a similar $\mu$ value to the P III fractions. The value of $\mu$ found is 17,900 calories per mole.

\section{The Relation between Time and Concentration.-}

Ponder (15) has shown that equation (3) can be used satisfactorily for the characterization of many hemolysins:

$$
d x / d t=K S(c-x)^{1 / p}
$$

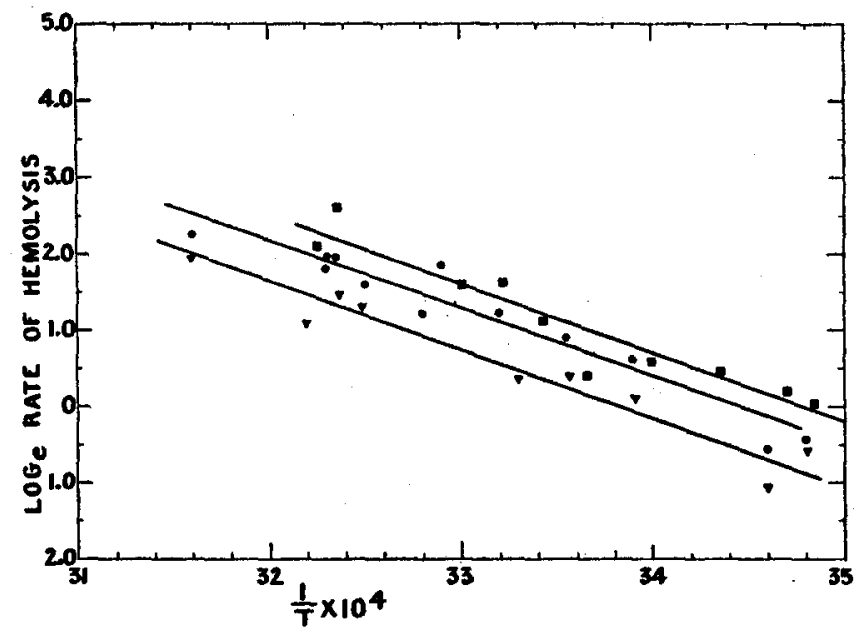

FIG. 4. Rate of hemolysis as a function of temperature.
, fraction P III
$2.0 \mathrm{H} . \mathrm{U} . / \mathrm{ml}$
$\nabla$, fraction P III
$1.0 \mathrm{H} . \mathrm{U} . / \mathrm{ml}$

$\square$, electrophoretically separated fraction $2.3 \mathrm{H} . \mathrm{U} . / \mathrm{ml}$.

By integration of (2)

$$
k t=\frac{p}{p-1}\left[c^{(p-1) / p}-(c-x)^{(p-1) / p}\right]
$$

In equations (2) and (3), $x$ is a measure of the extent to which the orderly state of the cell surface is modified; $c$ is the concentration of lysin in the hemolytic system, $S$ is the concentration of the cell component with which the lysin interacts; $p$ is an arbitrary constant, and $k$ in $(3)=K S$.

The experiments presented below were carried out in phosphate saline buffers (M/12.9 $\mathrm{NaCl}$ and $\mathrm{M} / 15$ mono- and disodium phosphate), at $37 \pm 0.5^{\circ}$. The final mixture contained half a volume of a 1 per cent suspension of rabbit erythrocytes. Samples were withdrawn at intervals of 6 to 15 minutes, centrifuged at $1^{\circ}$, and the concentration of hemoglobin in the supernatant determined colorimetrically. The time required for 50 per cent hemolysis at each initial concentration was estimated from percentage hemolysis curves. All determinations for a given $\mathrm{pH}$ value were carried out on the same day. 
The curve predicted from equation (3) for the plot of $1 / v$ (the dilution of hemolysin) against time should be a curve uniformly concave to the $t$-axis. The data presented here do not fit this equation. The points were found to lie on a sigmoid curve (Fig. 5). This occurred over the entire $\mathrm{pH}$ range. The 50 per cent end-point was chosen for this test since it was felt that the greater accuracy of the colorimetric over the visual test warranted the labor and

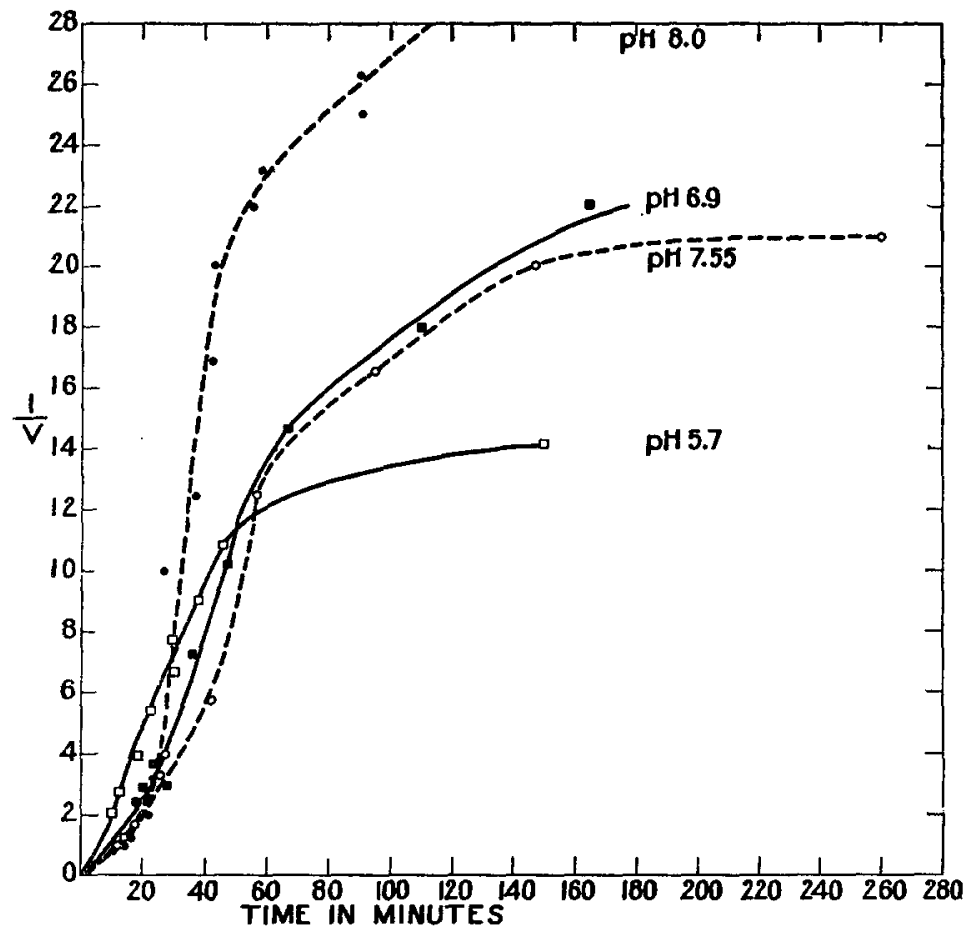

Fic. 5. Time dilution curves for hemolysin $\mathrm{S}$ and rabbit erythrocytes at various hydrogen ion concentrations $\left(37 \pm 0.5^{\circ} \mathrm{C}.\right) \cdot\left(\frac{1}{v} \ldots\right.$ dilution; $\frac{1}{v} \times 1.75 \times 10^{-9} \ldots$ mg. $\mathrm{N}$ of $\mathrm{P}$ III in final mixture).

expenditure of materials. Similar curves, however, were obtained by visual observation of the time required for complete hemolysis. They were of the same general form as those obtained from the 50 per cent end-points. The electrophoretically isolated fraction also gave a sigmoid curve for the plot of dilution against time.

Inhibition by Lipids. - The fact that streptolysin $\mathrm{O}$ and $\mathrm{S}$ can be distinguished by their relative behavior in the presence of cholesterol and lecithin (16) led to a reinvestigation of this inhibition on the purified streptolysin S. 
The following lipid preparations were used for this investigation: animal lecithin (lecithin A, Pfanstiehl Chemical Co.), beef heart lecithin (lecithin B, Lederle), soyabean phosphatid and animal cephalin (Nutritional Biochemical Corp.), and cholesterol, v.S.P. Suspensions of the lipids were prepared by shaking them in phosphate buffer; the beef heart lecithin was obtained in an alcoholic solution and $1 \mathrm{ml}$. of this solution was suspended in $100 \mathrm{ml}$. of phos-

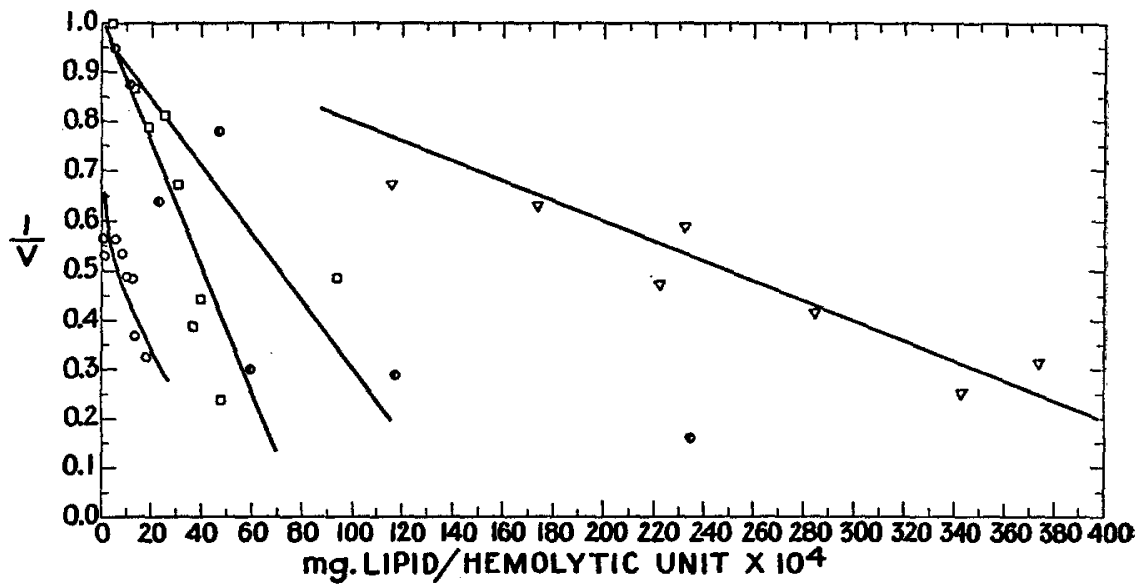

Frg. 6. The inhibiting effect of various lipid preparations on streptolysin $S$ ( $v$. . volume containing $1 \mathrm{H} . \mathrm{U} ., \mathrm{v}=1$ in the absence of lipids).

0 , beef lecithin (Lederle).

C, cephalin.

$\square$, soya bean phosphatide.

$\nabla$, animal lecithin (Pfanstiehl Chemical Co.).

TABLE V

The Inhibition of Streptolysin $S$ by Various Lipid Preparations

\begin{tabular}{c|c|c}
\hline Lipid & $\begin{array}{c}\text { Lipid required for 50 } \\
\text { per cent inhibition }\end{array}$ & Iodine No. \\
\hline & $\begin{array}{c}\text { mg. } \text { B.U. } \\
\text { Lecithin A }\end{array}$ & \\
" B B & $7 \times 10^{-4}$ & 54.9 \\
Soya bean phosphatid & $41 \times 10^{-4}$ & 86.1 \\
Cephalin & $72 \times 10^{-4}$ & 74 \\
\hline
\end{tabular}

phate saline. Varying quantities of the suspensions were added to the hemolysin (P III), the mixtures were incubated for 5 minutes, and the activity of each mixture tested in the usual way (Fig. 6).

Cholesterol and choline had no influence on hemolysis. Beef heart lecithin (Lederle) was the most effective inhibitor among the lipids tested. The inhibitive power of cephalin suggests either that cephalin contains an impurity which is the actual inhibitor, or that cephalin is the inhibitor per se (Table V).

The question naturally arose as to which phase of hemolysis is inhibited by 


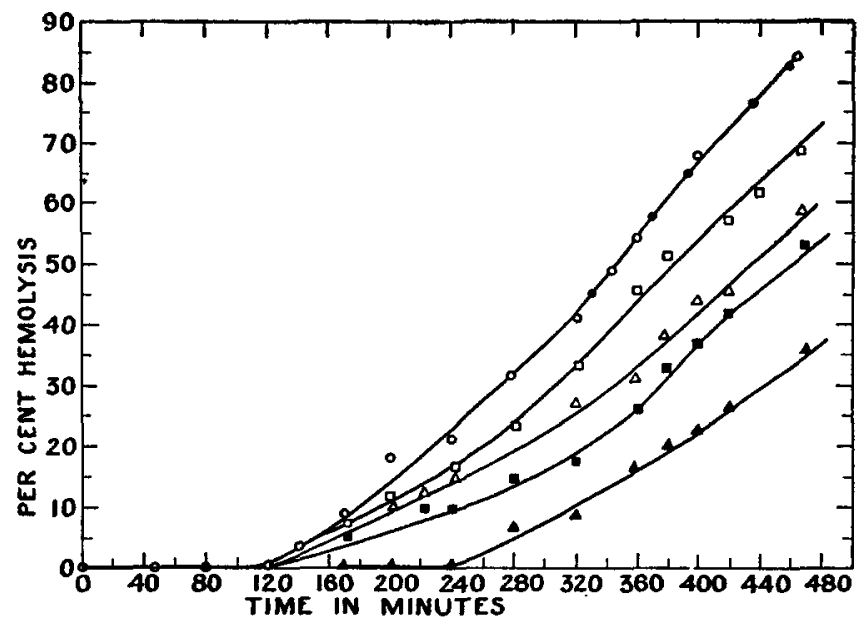

FIG. 7. The inhibition of hemolysis by beef heart lecithin (B); rate of hemolysis at $14^{\circ} \mathrm{C}$ : $O$, in the absence of lecithin.

- lecithin added 320 minutes after mixing erythrocyte suspension and streptolysin S.

$\square$, lecithin added 140 minutes after mixing erythrocyte suspension and streptolysin $S$.

$\Delta$, lecithin added 80 minutes after mixing erythrocyte suspension and streptolysin $S$.

$\mathbf{W}$ lecithin added 45 minutes after mixing erythrocyte suspension and streptolysin $\mathrm{S}$.

$\Delta$, lecithin added to hemolysin 5 minutes before mixing erythrocyte suspension and streptolysin S.

Each solution contained 1 H.U. per ml. of streptolysin S and 0.0019 mg. of lecithin (B) per H.U.

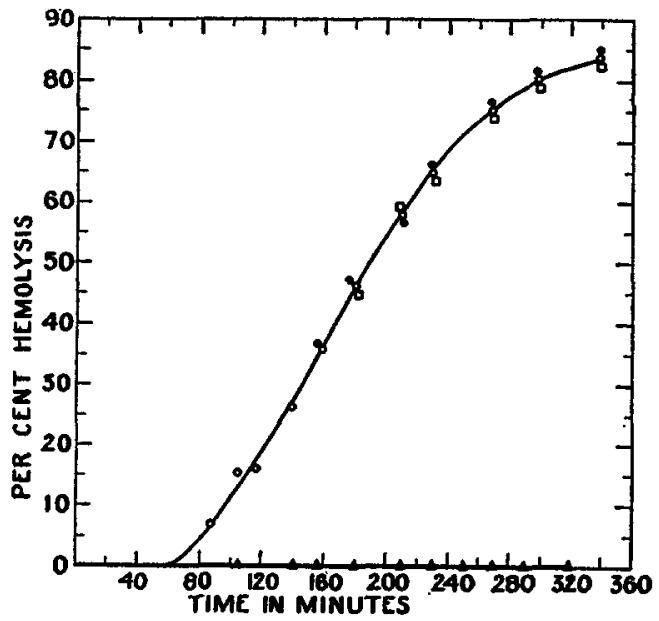

Fie, 8. The inhibition of hemolysis by animal cephalin; rate of hemolysis at $14^{\circ} \mathrm{C}$

$O$, in absence of cephalin.

$\square$, cephalin added 165 minutes after mixing.

-, cephalin added 60 minutes after mixing.

$\Delta$, cephalin added 5 minutes before mixing 2 H.U. of streptolysin S per ml. and 0.0085 mg. cephalin/H.U. 
lecithin and perhaps cephalin. Since the duration of the lag phase increases with decreasing temperature, a low temperature is most suitable for an investigation of the events occurring during the lag phase.

Mixtures of $50 \mathrm{ml}$, of a 1 per cent cell suspension and fraction P III in a suitable dilution were incubated at $14^{\circ}$. The final volume was made up to $100 \mathrm{ml}$. with phosphate buffer $(\mathrm{pH} 6.85 \pm 0.05)$. Constant amounts of lipid were added either before or after the addition of red cells to constant amounts of lysin. The degree of hemolysis was followed as a function of time.

It will be seen from Fig. 7 that the addition of lecithin B to streptolysin S before the addition of red cells caused considerable inhibition of lysis. The addition of lecithin $B$ to a mixture of lysin and red cells resulted in an inhibition if added sufficiently early in the incubation period. Similar observations were made with cephalin (Fig. 8).

\section{DISCUSSION}

A highly purified preparation of streptolysin $S$ has been obtained from bacterial filtrates of Streptococcus pyogenes by fractionation with methanol under controlled conditions of temperature, hydrogen ion concentration, and ionic strength. Fraction P III showed a 390-fold increase of hemolytic units $/ \mathrm{mg}$. $\mathrm{N}$ over the most potent bacterial filtrate prepared by the growth of $S$. pyogenes $\mathrm{C} 203 \mathrm{~S}$ on the synthetic medium of Bernheimer et al. $(7,8)$.

Herbert and Todd found (3) that at low temperatures 1 to 2 hemolytic units of streptolysin $\mathrm{O}$ could be adsorbed on their erythrocyte suspensions before hemolysis commenced. In analogous experiments with streptoly in S (Table IV), there was always a large part of the hemolysin left in the supernatant even when the release of hemoglobin had already commenced. While there is, therefore, little doubt that streptolysin $O$ (and also pneumolysin) (17, 18) combines irreversibly with the erythrocytes before hemolysis commences, this does not occur with streptolysin S.

There is a characteristic lag period between the time at which the streptolysin $\mathrm{S}$ has been added to red cells and the actual onset of hemolysis; a property which it shares with Cl. seplicum hemolysin $(19,20)$.

Lecithin and cephalin appear to inhibit the action of streptolysin $S$ by combination with it. These lipids are known to occur in the cell surface of the erythrocyte (15) and they may compete with the substrate for the streptolysin. However, they may be the primary site of attachment but not of action, and this might account for the prolonged lag period. If lecithin is added to streptolysin $\mathrm{S}$ before the addition of red cells, it prolongs the lag period and decreases the rate of hemolysis. If the lecithin is added after the streptolysin $S$ has been mixed with the suspension of red blood corpuscles it decreases the rate of hemolysis, and the effect is greater the earlier the lecithin has been added to the mixture. It ceases to have an effect long before hemolysis is complete 
(at 40 per cent hemolysis under the conditions of the experiment shown in Fig. 7). It would appear as if at this stage the reaction between the cell and the streptolysin $S$ with which the lecithin interferes had gone to completion. The reaction involved would thus dominate the lag period.

Streptolysin $\mathrm{S}$ obeys the Arrhenius equation over a temperature range of $14^{\circ}$ to $40^{\circ}$. There is little doubt that hemolysis is not the result of one simple chemical reaction which leads to the release of hemoglobin, but rather of a chain of reactions. It is unlikely that two or more concurrent chains of reactions with different heats of activation are involved and that each contributes appreciably to the measured rate, because this would result in a curve which would be concave or convex to the ordinate (21). If only one chain of reactions is responsible for hemolysis, the slowest will, of course, be the master reaction and the heat of activation will be attributable to it.

Since two stages in the process of hemolysis can be distinguished in the case of streptolysin S, it is of interest to consider which stage is more likely to determine the rate of reaction. The time of the lag period is about one-third of that required for the attainment of 50 per cent hemolysis, once hemolysis has commenced. The rate of reaction is determined from the straight portion of the per cent hemolysis time curve near the 50 per cent point. Although the primary reaction may continue after hemolysis has commenced, it can be assumed that the reaction occurring during the lag period is faster than the secondary reaction and is completed in the region from which the rate is determined. Thus, the heat of activation is characteristic for the reaction following the one occurring during the lag period.

The heat of activation of streptolysin $S$ found here is 17,900 calories per mole. A value of 14,600 has previously been reported by Bernheimer (23) using human erythrocytes and crude streptolysin S.

The equation which Ponder has found to apply to many hemolytic systems does not fit the data on streptolysin S. It thus might be of interest to see what further assumptions would have to be made to reconcile these results with the general equation. It could be considered that the sigmoid curve is due to an impurity which is present in amounts proportional to the streptolysin S. For this to be the case, the plot of $c_{1}: c_{2}{ }^{3}$ against the concentration of inhibitor (or hemolysin) would need to give a curve concave to the $c_{1}: c_{2}$ axis. Since the electrophoretically separated hemolysin behaves in the same way as P III, the likelihood of the presence of such an inhibitor is decreased if not excluded.

It should be remarked that there are several other known instances in which sigmoid curves, or curves not uniformly concave to the abscissa are obtained when the dilution of a lysin is plotted against time (15). It has been suggested

${ }^{3} c_{1}: c_{2}$, ratio of the concentration of hemolysin producing a certain degree of hemolysis in the presence of an inhibitor to the concentration of the hemolysin which will produce the same degree of hemolysis in the absence of the inhibitor (15). 
(22) that these atypical forms of curve are given by mixed or impure lysins, but both pure sodium taurocholate and sodium glycocholate give atypically shaped curves, which in some pH ranges are sigmoid. ${ }^{4}$

\section{SUMMARY}

Considerable purification of streptolysin $\mathrm{S}$ has been achieved by fractionation of crude bacterial filtrates with methanol, under controlled conditions of $\mathrm{pH}$, ionic strength, and temperature. The final material (P III) consisted of two electrophoretic components.

The purified material was employed for kinetic studies, the results of which were confirmed with hemolysin isolated electrophoretically from P III.

The heat of activation (temperature characteristic) of streptolysin $S$ was found to be 17,900 calories per mole.

Time dilution curves of the hemolysin were found to be sigmoid.

The influence of certain ions and lipids on the course of hemolysis was investigated.

The significance of the prolonged lag period and of the deviation in the behavior of streptolysin $\mathrm{S}$ from Ponder's equation has been discussed.

Thanks are due to Dr. H. D. Piersma and Dr. J. N. Adam, Jr., of Lederle Laboratories Division, American Cyanamid Company, for the bacterial filtrates from Streptococcus pyogenes, and beef heart lecithin; to Dr. E. Ponder for valuable suggestions and discussions, to Dr. A. W. Bernheimer for the strain C203S of Streptococcus pyogenes, and to Mrs. F. Pollard for able technical assistance.

This investigation was supported in part by a grant from Lederle Laboratories Division, American Cyanamid Company, and in part by a research grant from the National Institutes of Health, Public Health Service.

\section{BIBLIOGRAPHY}

1. Marmorek, A., Ann. Inst. Pasteur, 1895, 9, 523.

2. Todd, E. W., J. Path. and Bact., 1938, 47, 423.

3. (a) Herbert, D., and Todd, E. W., Biochem. J., 1941, 35, 1124.

(b) Herbert, D., Biochem. J., 1941, 35, 1116.

(c) Herbert, D., and Todd, E. W., Brit. J. Exp. Path., 1947, 25, 242.

4. Smythe, C. V., and Harris, T. N., J. Immunol., 1940, 38, 283.

5. (a) Okamoto, H., Japan J. Med. Sc., IV., Pharmacol., 1940, 12, 167.

(b) Okamoto, H., Miura, K., Ito, R., and Kyoda, S., Japan J. Med. Sc., IV., Pharmacol., 1940, 13, 23.

6. Ito, R., Folia Pharmacol. Japon., 1940, 28, 41.

7. Bernheimer, A. W., and Rodbart, M., J. Exp. Med., 1948, 88, 149.

8. Bernheimer, A. W., Gillman, W., Hottle, G. A., and Pappenheimer, A. M., Jr., J. Bact., 1942, 43, 495.

9. Edsall, J. T., Advances Protein Chem., 1947, 3, 384.

10. Pillemer, L., and Robbins, K., Ann. Rev. Microbiol., 1949, 3, 265.

${ }^{4}$ Ponder, personal communication. 
11. Woodman, A. G., Food Analysis, New York and London, McGraw-Hill Publishing Co., Inc., 4th edition, 1941, 185.

12. Macfarlane, M. G., and Knight, B. C., Biochem. J., 1941, 35, 884.

13. Arrhenius, S., Quantitative Laws in Biological Chemistry, London, G. Bell and Sons, 1915.

14. Crozier, W. J., J. Gen. Physiol., 1925-26, 9, 531.

15. Ponder, E., Hemolysis and Related Phenomena, New York, Grune \& Stratton, Inc., 1948.

16. Hewitt, L. F., and Todd, E. W., J. Path. and Bact., 1939, 49, 45.

17. Fleming, W. L., and Neill, J. M., J. Exp. Med., 1927, 46, 755.

18. Cohen, B., Halbert, S. P., and Perkins, M. E., J. Bact., 1942, 43, 607.

19. Menk, W., Zentr. Bact., l. Abt., Orig., 1932, 123, 55.

20. Bernheimer, A. W., J. Exp. Med., 1944, 80, 333.

21. Crozier, W. J., J. Gen. Physiol., 1924-25, 7, 189.

22. Roy, A. C., J. Roy. Asiatic Soc. Bengal, 1949, $15,15$.

23. Bernheimer, A. W., J. Gen. Physiol., 1947, 30, 337. 